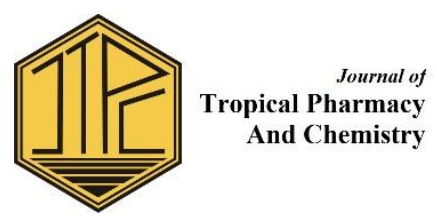

\title{
SUNSCREEN LOTION OF MIANA LEAVES (COLEUS ATROPURPUREUS BENTH)
}

\author{
Rolan Rusli ${ }^{1,2, *}$, Aditya Fridayanti ${ }^{1}$, Rosniah $^{1}$ \\ ${ }^{1}$ Laboratorium Penelitian dan Pengembangan Kefarmasian "Farmaka Tropis" \\ Fakultas Farmasi, Universitas Mulawarman, Samarinda, Indonesia \\ 2 Kelompok Bidang Ilmu Kimia Farmasi, Fakultas Farmasi, Universitas Mulawarman, \\ Samarinda, Indonesia \\ *email: rolan@farmasi.unmul.ac.id
}

\begin{abstract}
Sunscreen can protect the skin from UV radiation. One of the plants that have the potential to be used as active ingredients of sunscreen lotion is miana leaves (Coleus atropurpureus Benth). Lotion made in 3 formulas F1, F2 and F3. Lotion tested its stability with a freezethaw method, and evaluated organoleptic, homogeneity, $\mathrm{pH}$, viscosity and scatterness and tested sunscreen activity of lotion preparation. The preparation shows good homogeneity, and has oleum rosae odor and thick consistency with the lotion color is brown (F1), dark brown (F2) and slightly greenish brown (F3). Spreading, viscosity, and $\mathrm{pH}$ of the lotion meet the Indonesia Standard. The lotion formula comes in the category of fast tanning (F2) and extra protection $(\mathrm{F} 3)$ sunscreen
\end{abstract}

Keywords: lotion, miana leaves (Coleus atropurpureus Benth), sunscreen, \% Te, \% Tp

Submitted on: 12 September 2018

Accepted on: 03 June 2019

DOI: https://doi.org/10.25026/jtpc.v4i5.135

\section{INTRODUCTION}

Research about miana leaves has a lot because miana leaves have many benefits, because they contain secondary metabolite compounds such as saponins [1], flavonoids, polyphenols, and essential oils [2]. One of the benefits of miana leaves is antioxidants. The antioxidant activity of ethanol extract of miana leaves is quite high because $\mathrm{IC}_{50}$ value is $48.04 \mathrm{ppm}$ [3]. Miana leaves can be optimized for its potency because miana leaf is bush plant which can be easily cultivated. In addition miana leaves in some areas can be used as vegetable (edible) so it is not toxic if applied further.

In addition, ethanol extract at a concentration of $250 \mathrm{ppm}$ miana leaves also has sunblock activity seen from $\% \mathrm{Te}$ and $\% \mathrm{Tp}$, as well as the category of standard suntan [4]. Similarly, Miana leaves also have activity as sunscreen seen from sun protection factor (SPF) values [5]. However, research on the potential of 
sunscreen lotions from miana leaves has not been reported, so in this article it is reported about the potential of sunscreen lotion preparations from miana leaves.

\section{METHODS}

\section{Extraction and Formulation of Lotion}

Miana leaves was colected, sorted, and washed, thinly sliced, and dried at room temperature. Dry of miana leaves was extracted by maceration method using n-hexane, ethyl acetate, and ethanol solvent. A Solution of extracts was concentrated using a rotary evaporator and evaporated over the water bath to obtain a dry ethanol extract [5]. Ethanol extract of miana leaves was formulated into a lotion with various extract concentration of miana leaves (Table 1). Lotion was prepared by separated into two parts: the water phase and the oil phase. The oil phase i.e. stearic acid and liquid paraffin are diluted at 70 ${ }^{\circ} \mathrm{C}$. The ingredients include water phases such as propylene glycol, TEA, methyl paraben, propyl paraben and residual water mixed at $70{ }^{\circ} \mathrm{C}$ and homogenous. Then the oil phase is introduced bit by bit into the water phase at $70{ }^{\circ} \mathrm{C}$ while stirring until homogeneous and forming a lotion base. After that, it was allowed to stand at room temperature to $40{ }^{\circ} \mathrm{C}$ and put the ethanol extract of miana leaves bit by bit into the base and then added with oleum rosae stirred to form a lotion preparation of miana leaf ethanol extract

\section{Freeze-thaw stability test}

Stability test is done by freeze-thaw method. Each lotion was placed at cold temperature $\left( \pm 4{ }^{\circ} \mathrm{C}\right)$ for $2 \times 24$ hours then placed at hot temperature $\left(40 \pm 2{ }^{\circ} \mathrm{C}\right)$ for $2 \times 24$ hours, counted 1 cycle. Testing is done up to 6 cycles, then evaluated the physical and chemical properties of lotion.

\section{Organoleptic test}

Organoleptic testing is performed by observing odor, color, and consistency of lotion.

\section{Homogeneity test}

Testing is done by taking lotion then applied on transparent glass then observed their homogeneity.

\section{pH test}

The test was performed by $\mathrm{pH}$ meter calibration, electrode was washed and rinsed with distilled water then put into the lotion and determined $\mathrm{pH}$ lotion.

\section{Viscosity test}

The test was performed using a Rheosys Cone and Plate viscometer at 10 rpm. Lotion ( $1 \mathrm{~g})$ was placed on the plate and then lowered the cone and run the viscometer and measured its viscosity.

\section{Spreading capacity test}

Lotion $(0.5 \mathrm{~g})$ is placed in the center of a spherical glass. On top of the material is placed another round glass then silenced for 1 minute then recorded the spread. Each stage is loaded with a weight of 50 grams and silenced for 1 minute and then recorded the spread. The ballast is added up to 250 grams. Spread was recorded on 4 sides.

\section{Sunscreen Activity test of Lotion}

Lotion $(0.1 \mathrm{~g})$ was dissolved in $95 \%$ to $10 \mathrm{~mL}$ ethanol to obtain a test concentration of $10,000 \mathrm{ppm}$. Each solution was measured up to $5 \mathrm{~nm}$ in the wavelength range of erythema and pigmentation 272.5-372.5 $\mathrm{nm}$ then calculated of $\% \mathrm{Te}$ and \% $\mathrm{Tp}$. Determination of sunscreen category based $\% \mathrm{Te}$ and \% Tp values [6].

\section{RESULTS AND DISCUSSION}

The sunscreen lotion formulated with the active ingredients of the ethanol 
extract of miana leaf are tabulated in table 1. The concentration of ethanol extract of miana leaves on F1, F2 and F3 formulas were $1 \%, 1.5 \%$, and $2.5 \%$, respectively. The results of organoleptic testing and observation are presented in Table 2 and Figure 1, and the results of $\mathrm{pH}$ observation, scattering, and viscosity are presented in Table 3.

Table 1. Lotion formula of ethanol extract miana leaves

\begin{tabular}{lcccc}
\hline \multirow{2}{*}{ Material } & \multicolumn{4}{c}{ Formulation (\%) } \\
\cline { 2 - 5 } & Base & F1 & F2 & F3 \\
\hline Ethanol extract of miana leaves & - & 1 & 1.5 & 2.5 \\
Propylene glycol & 15 & 15 & 15 & 15 \\
Triethanolamine & 1 & 1 & 1 & 1 \\
Liquid Paraffin & 7.5 & 7.5 & 7.5 & 7.5 \\
Stearic acid & 3 & 3 & 3 & 3 \\
Methylparaben & 0.2 & 0.2 & 0.2 & 0.2 \\
Propylparaben & 0.02 & 0.02 & 0.02 & 0.02 \\
Oleum rosae & 3 drops & 3 drops & 3 drops & 3 drops \\
Water & ad $100 \mathrm{~mL}$ & ad $100 \mathrm{~mL}$ & ad $100 \mathrm{~mL}$ & ad $100 \mathrm{~mL}$ \\
\hline
\end{tabular}

Table 2. Result of organoleptic analysis

\begin{tabular}{cccc}
\hline \multirow{2}{*}{ Formulation } & \multicolumn{2}{c}{ Organoleptic } \\
\cline { 2 - 4 } & Colour & Odour & Properties \\
\hline Base & White & No smell & Viscous, in cycle 3-6 the viscosity decreases \\
F1 & Brown & Oleum rosae & Slightly viscous, in cycles 1-6 fluctuated \\
F2 & Dark Brown & Oleum rosae & Viscous, tends to decrease until the 6th cycle \\
F3 & Greenish Brown & Oleum rosae & Viscous, in cycle 1-6 fluctuated \\
\hline
\end{tabular}

Table 3. Data of $\mathrm{pH}$, Spreading capacity, and Viscosity of Lotion

\begin{tabular}{|c|c|c|c|c|c|c|c|}
\hline \multirow{2}{*}{ Formulation } & \multicolumn{7}{|c|}{ Cycle } \\
\hline & S0 & $\mathrm{S} 1$ & $\mathrm{~S} 2$ & S3 & S4 & S5 & S6 \\
\hline \multicolumn{8}{|l|}{$\mathrm{pH}$} \\
\hline Base & 8.24 & 8.09 & 8.23 & 8.26 & 8.28 & 8.21 & 8.03 \\
\hline F1 & 7.07 & 7.08 & 7.10 & 7.09 & 7.09 & 7.06 & 7.07 \\
\hline $\mathrm{F} 2$ & 6.80 & 6.83 & 6.84 & 6.87 & 6.89 & 6.83 & 6.87 \\
\hline F3 & 6.72 & 6.74 & 6.73 & 6.73 & 6.68 & 6.58 & 6.55 \\
\hline \multicolumn{8}{|l|}{ Spreading capacity $(\mathrm{cm})$} \\
\hline Base & 10.36 & 10.76 & 10.46 & 11.13 & 11.06 & 11.06 & 11.00 \\
\hline $\mathrm{F} 1$ & 9.06 & 9.63 & 10.13 & 10.00 & 10.36 & 9.10 & 10.36 \\
\hline $\mathrm{F} 2$ & 8.67 & 9.57 & 10.00 & 9.06 & 9.83 & 8.96 & 10.1 \\
\hline F3 & 7.86 & 9.20 & 9.06 & 9.20 & 9.10 & 9.16 & 9.16 \\
\hline \multicolumn{8}{|l|}{ Viscosity (Pa.s) } \\
\hline Base & 1.2175 & 1.1750 & 1.2248 & 0.9185 & 0.8672 & 0.8669 & 0.8636 \\
\hline $\mathrm{F} 1$ & 0.8864 & 0.4978 & 0.5097 & 0.6957 & 0.6277 & 0.7717 & 0.4170 \\
\hline $\mathrm{F} 2$ & 1.4385 & 0.8350 & 0.7191 & 0.8002 & 0.6737 & 0.7568 & 0.6599 \\
\hline F3 & 1.8772 & 0.7809 & 1.0285 & 0.8488 & 0.9166 & 0.8588 & 0.8697 \\
\hline
\end{tabular}




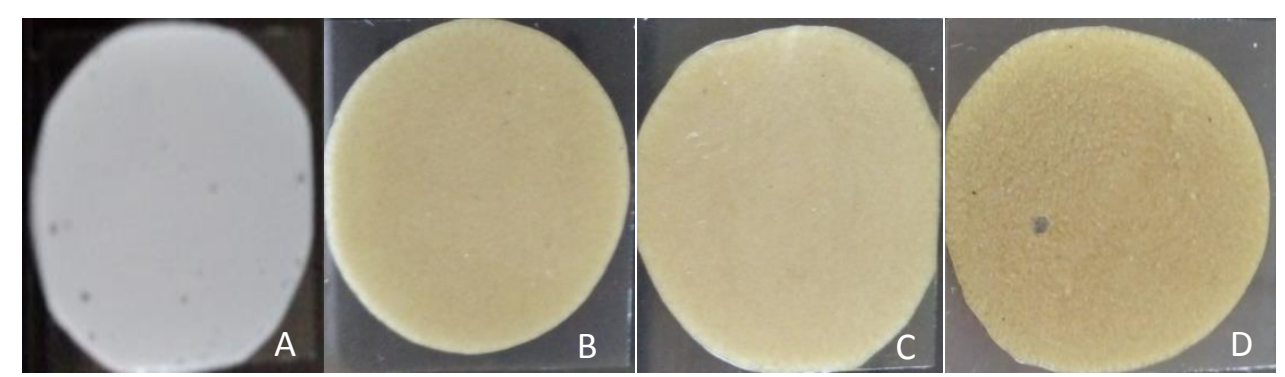

Figure 1 Homogeneity of Lotion, (A) Base, (B) F1, (C) F2, and (D) F3

Table 4. Sunscreen Category of Lotion from Ethanol Extract of Miana Leaves

\begin{tabular}{cccc}
\hline \multirow{2}{*}{ Formulation } & \multicolumn{2}{c}{ Sunscreen Activity } & Sunscreen \\
\cline { 2 - 3 } & $\% \mathrm{Te}$ & \% & Category $[6]$ \\
\hline F1 & 21.91 & 21.56 & - \\
F2 & 16.57 & 16.48 & Fast tanning \\
F3 & 3.85 & 3.53 & Extra Protection \\
\hline
\end{tabular}

Organoleptic observations of F1, F2 and F3 lotion are brown, dark brown, and greenish brown, respectively. All three formulas have oleum rosae odor and a thick consistency. The homogeneity test of F1, F2 and F3 lotion showed good homogeneity.

Spreading capacity and $\mathrm{pH}$ of lotion indicated that the lotion had met the standard in accordance with Indonesian Standard [7]. The spread of lotion showed that the higher the concentration of ethanol extract of miana leaves, the lower the distribution power. This is inversely related to the viscosity of the lotion, i.e. the higher the concentration of the extract, the higher the viscosity of the lotion.

Table 4 shows that there are difference activity of sunscreen between F1, F2, and F3 lotion.

The viscosity of the lotion during storage tends to decrease during storage until the last cycle. The decrease in viscosity may be caused by decreased emulsion stability over time.
The result of measurement and calculation of $\% \mathrm{Te}$ and $\% \mathrm{Tp}$ value and sunscreen lotion category with active ingredients of miana leaves extract are presented in table 4. Lotion included in sunscreen assessment category are F2 and $\mathrm{F} 3$ lotion where lotion $\mathrm{F} 2$ is included in fast tanning category while lotion F3 is included in the category of extra protection.

Based on the data in Table 4, it can be seen that there is a difference in sunscreen activity between F1, F2 and F3 lotion. The \% Te and \% $\mathrm{Tp}$ value of $\mathrm{F} 3$ lotion have the least value compared to other lotions. The sunscreen category is inversely proportional to the $\% \mathrm{Te}$ and $\%$ $\mathrm{Tp}$ values. Thus, the F3 lotion has the best sunscreen activity compared to other lotions. This is because F3 lotion has the concentration of extract ethanol leaves miana largest so that the content of compounds that have the potential as a sunscreen. The more compounds contained the more effective the compound is to absorb or block UV light so that the amount 
of light is passed slightly and the value of $\%$ Te and \% Tp produced even smaller.

\section{CONCLUSION}

Ethanol extract of Miana Leaves with $2.5 \%$ can be formulated to sunscreen lotion as extra protection category.

\section{REFERENCES}

[1] Rijai, L., Beberapa Tumbuhan Obat Asal Kalimantan Timur Sebagai Sumber Saponin Potensial. Journal of Tropical Pharmacy and Chemistry, 2012, 1, (4), 297-302 DOI: https://doi.org/10.25026/jtpc.v1i4.40.

[2] Depkes-RI, Inventaris Tanaman Obat Indonesia Jilid 1. Jakarta: Badan Penelitian dan Pengembangan Kesejahteraan Depkes RI, 2000.

[3] Sari, D.D., Uji aktivitas Antioksidan Ekstrak Daun Miana (Coleus Atropurpuresus L. Benth.) terhadap $D P P H$ (1,1-Diphenyl-2-
Picrylhidrazyl. 2013, Mulawarman University: Samarinda.

[4] Amrillah, M.S., R. Rusli, and J. Fadraersada, Aktivitas Tabir Surya Daun Miana (Coleus atropurpureus L. Benth) Secara In Vitro. Jurnal Sains dan Kesehatan, 2015, 1, (4), 168-174 DOI: https://doi.org/10.25026/jsk.v1i4.35.

[5] Rosniah, R., R. Rusli, and A. Fridayanti. Penentuan Nilai Sun Protection Factor Aktivitas Tabir Surya Ekstrak Etil Asetat Daun Miana (Coleus atropurpureus) Secara In Vitro. Proceeding of Mulawarman Pharmaceuticals Conferences. 2016. DOI:

https://doi.org/10.25026/mpc.v3i2.136

[6] Balsam, M.S., Cosmetics: science and technology. 1974: John Wiley \& Sons.

[7] SNI-16-4399-1996, Sunscreen Preparation (National standardization agency of Indonesia). 1996. 